\section{Abstract}

School-based fire safety education programs are implemented by fire services organisations around the world to improve children's fire safety knowledge and skills. Such education is considered the single most modifiable strategy that fire services organisations can implement to reduce the risk that children will misuse fire or be harmed by fire. Despite this, there are no overarching and evidence-based guidelines for the development of new programs or the evaluation and modification of existing ones. To fill this void, a rapid evidence assessment of existing literature was conducted. Results revealed 25 evidence-based practices that held true in a variety of contexts and methodologically diverse studies. These practices inform an empirical framework that can be used to guide fire safety education programs for children.

\title{
Evidence-based practices of effective fire safety education programming for children
}

Peer Reviewed

\section{Kamarah Pooley ${ }^{1}$}

Sonia Nunez ${ }^{1}$

Mark Whybro ${ }^{1}$

1 Fire and Rescue New South Wales, Sydney, New South Wales.

\section{SUBMITTED}

7 October 2020

\section{ACCEPTED}

23 November 2020

\section{DOI}

www.doi.org/10.47389/36.2.34

\section{(c) (1) (2)}

(C) 2021 by the authors.

License Australian Institute for Disaster Resilience,

Melbourne, Australia. This is an open access article distributed under the terms and conditions of the Creative Commons Attribution (CC BY) license (https:// creativecommons.org licenses/by/4.0/).

\section{Introduction}

Fire services organisations implement community risk reduction mechanisms to improve fire prevention and preparedness (Simpson et al. 2014). One such mechanism, fire safety education for children, plays a pivotal role in fire prevention and preparedness (Brown 2019; Huseyin \& Satyen 2006; Satyen, Barnett \& Sosa 2004). School-based fire safety education programs are implemented around the world to improve children's fire safety knowledge and skills (Kendrick et al. 2007; Satyen, Barnett \& Sosa 2004). These programs aim to enhance children's understanding of fire and how to respond appropriately to reduce the likelihood they will misuse fire or be harmed by fire (Kendrick et al. 2012).

According to Monk (2011), prevention through education is the single most modifiable strategy that fire services organisations can adopt to reduce the risk of fire to children. School-based fire safety education programs are generally delivered by firefighters during school visits that occur periodically or as stand-alone programs in isolation or coupled with teacher-delivered components (Satyen, Barnett \& Sosa 2004). Despite widespread implementation of fire safety in schools, there are no overarching and evidence-based guidelines informing the development of new programs or the evaluation of existing ones (Simpson et al. 2014). This is problematic where empirically derived knowledge is required to determine what works in fire safety education for children (Huseyin \& Satyen 2006, Simpson et al. 2014). To fill this void, a rapid evidence assessment of literature was conducted that revealed 25 evidence-based practices that held true in a variety of contexts and methodologically diverse studies.

\section{Aim}

This research is important because it contributes to the body of knowledge concerned with fire safety education. The use of an overarching, evidence-based framework will promote rigour, consistency and effectiveness in fire safety education to enhance the capacity of fire services organisations to reduce the risk of fire to children. 
M RESEARCH

\section{Methodology}

A rapid evidence assessment collects relevant empirical evidence about a topic, collates the data and allows for a meta-analyse to summarise existing research (Barends, Rousseau \& Briner 2017). Although this method systematically assesses existing literature, 'rapidity' is achieved by limiting breadth and scope (Barends, Rousseau \& Briner 2017; Varker et al. 2015). While this ensures a timely and rigorous review of the literature, the findings are limited to the methodology employed (Varker et al. 2015). Concessions to breadth and scope mean that the results should be couched in the methodology of the rapid evidence assessment and not the body of evidence.

To ensure methodological rigour while meeting time-sensitive needs, this study limited the scope of the research to the following search criteria. Studies were included if they were:

- scholarly, scientific or industry papers

- published in any country

- dated between 2000 and 2020

- in English

- theoretically or empirically evaluated or studied fire safety programs for children aged 0 to 17 years

- a form of primary prevention.

An iterative search with key words was used to search the library catalogue of Fire and Rescue New South Wales and Google (child* OR young person OR adolescent* OR youth OR juvenile AND fire AND educat* OR school OR prevent* OR program*).

Ninety sources were identified, 22 of which were excluded after abstract review. A further 17 were excluded after full-text review because they did not meet the selection criteria. A total of 51 sources were included in the rapid evidence assessment. Once the data were collected, coded and collated, it was qualitatively analysed. The findings revealed 25 evidence-based practices of effective fire safety education programs for children. These practices related to 7 main themes of theory of change, target, approach, content, resources, implementation and evaluation.

\section{Results and discussion}

\section{Theory of change}

Fire safety education should explicitly identify the theory of change underpinning program activities

Fire safety education programs are generally underpinned by the premise that children have limited capacity to understand the risks and consequences of fire and an inability to react promptly and rationally to fire (Chen et al. 2011; Harpur, Boyce \& McConnell 2012; Phillips 2012; Smith et al. 2018; UK Office of the Deputy Prime Minister 2003). This lack of knowledge and awareness puts children at risk of misusing fire or being harmed by fire. Fire safety education aims to improve children's knowledge and awareness of fire and fire safety to reduce this risk (Cakiroglu \& Gokoglu 2019, Dukes et al. 2016, Subramaniam 2004). If children are aware of the risk posed by fire, the need for immediate response to fire and knowledge of fire safety, they will be more likely to behave and respond appropriately (Office of the Advocate for Children and Young People 2020, Subramaniam 2004). Although this theory of change underpinned most of the sources reviewed, many did not explicitly identify the theoretical underpinnings of the programs. Fire safety education programs should explicitly identify the theory of change to help facilitators understand how the program activities lead to intended effects.

\section{Target}

Fire safety education should be tailored to the developmental stages of children

It is important to expose children to fire safety as early as possible when their sensory input is high (Jankowski 2015). Where generic fire safety education is more effective for primary school-aged children than preschool or kindergartenaged children (Chavez et al. 2014), it is necessary to ensure that programs are implemented in age-appropriate increments (Jankowski 2015; Satyen, Barnett \& Sosa 2004). This can be achieved by tailoring fire safety education to the developmental stages of children (Gielan et al. 2010; Lidstone 2006). Although not absolute, developmental stages provide a standard and commonly accepted classification of children by age (Giesler 2017).

\section{Approach}

Fire safety education should be mapped to the education curriculum

Fire safety education must be mapped to the education curriculum to allow for integration with school lessons (Phillips 2012). Direct alignment is essential where an overcrowded curriculum constrains opportunities for the delivery of standalone programs (Towers \& Whybro 2017). A standardised, integrated curriculum that connects the physical and social world and helps children understand the complexities of fire, hazards and disaster risk has been linked to a reduction in fear and increased preparedness (Phillips 2012, Ronan \& Towers 2014). If fire safety is mapped to the curriculum, students can be assessed and programs can be evaluated against curriculum-based outcomes. It is critical that fire safety programs also align with the relevant education rubrics for assessment and evaluation.

\section{Child-centred disaster risk reduction mechanisms should be ingrained within fire safety education}

Child-centred disaster risk reduction (CCDRR) draws on the rights, needs and capacities of children to reduce risk and enhance resilience (Back, Cameron \& Tanner 2009). CCDRR positions children as dynamic agents of change who can contribute to prevention and preparedness within their households and communities, influence response to fire and grow from the challenges associated with fire (Hayes, Lassa \& Towers 2010; Office of the Advocate for Children and Young People 2020). CCDRR can be included in fire safety education by empowering children to actively engage with and maintain ownership over program activities (Back, Cameron \& Tanner 2009; Office of the 
Advocate for Children and Young People 2020). CCDRR learning should be inquiry-driven, action-oriented and interactive (Brown 2019, Gielan et al. 2010), while also connecting with communities and a social consciousness (Hayes, Lassa \& Towers 2010).

\section{Structure}

Fire safety education should be teacher delivered and firefighter reiterated

Stand-alone firefighter-delivered fire safety education is not sufficient to reduce fire-related risks for children (Jankowski 2015, Monk 2011), meaning that firefighters should not be the primary source of fire safety education (Gerald 2019, Ogier 2008). Instead, fire safety education is more effective when educators teach fire safety concepts and skills to children, and firefighters reiterate lessons learnt (Monk 2011). This requires a coordinated approach (Jankowski 2015, Monk 2011, Ogier 2008). While teachers are best placed to provide age-appropriate and accessible education, coupled with opportunities to practice and consolidate lessons learnt (Gerald 2019; Towers et al. 2014), firefighters are best placed to familiarise children with aspects related to firefighter equipment and appearance and their roles (Gerald 2019). It is important that the firefighter-delivered component of the program does not become an entertainment or goodwill exercise (Ogier 2008). Focusing on the fire truck and playing with water hoses can distract children from the fire safety messages and may impede program effectiveness (Ogier 2008).

Fire safety education should implement the 'instruction, modelling, rehearsal and feedback' approach

Evidence suggests that fire safety should be taught using the 'instruction, modelling, rehearsal and feedback' approach (Cakiroglu \& Gokoglu 2019, Dukes et al. 2016, Giesler 2017). Instruction refers to the information given to children about the correct behaviours in specific situations. Modelling refers to the imitation of demonstrated behaviour. Rehearsal refers to the practice of a newly learnt behaviour. Feedback refers to positive reinforcement when behaviours are modelled correctly and instructive feedback when they are not (Cakiroglu \& Gokoglu 2019, Dukes et al. 2016). Importantly, this approach has been identified as effective in teaching fire safety skills to children with learning or behavioural problems (Dukes et al. 2016).

Fire safety education should be gain-framed, caregiver mediated and portrayed as a social norm

Children's understanding of fire safety messages is affected by framing and scripting (Borzekowski et al. 2013; Gielan, Borzekowski \& Rimal 2010). Fire safety messages that are gain-framed (show the correct behaviour followed by a positive outcome) and are combined with scripted caregiver mediation (discussion between the child and caregiver that follows predetermined talking points) are effective in communicating safety behaviours (Borzekowski et al. 2013; Gielan, Borzekowski \& Rimal 2010). Evidence also suggests that creating the perception that a certain behaviour is a social norm is effective in changing behaviour and reducing risk-taking by children
(Morrongiello \& Schwebal 2017). If children are exposed to gainframed messages and caregiver mediation, correct behaviour may be perceived as a social norm that, in turn, may instigate safe fire behaviour (Morrongiello \& Schwebal 2017).

Fire safety education should be short in duration and repeated over time to consolidate learning

Children need time to repeat and rehearse skills to consolidate learning and develop new skills (Gerald 2019, Jankowski 2015, Lidstone 2006, Rimmer et al. 2010). Fire safety should be delivered over several sessions to facilitate repetition (Jankowsk 2015). Further, younger children have shorter attention spans than older children and older children have shorter attention spans that adolescents (Gerald 2019, Lidstone 2006). Fire safety sessions should be short in duration, with lesson times adjusted to suit the developmental stages of children.

Fire safety education should be delivered using the 'multiple messages-multiple methods' approach

Not all children learn the same way. What works for some children will not work for others (Hickman \& Lawrence 2010, Lehna et al. 2013). Not all children experience the same risks, where culture, race, ethnicity and socio-economic disparities influence risk of fire and child injury (Istre et al. 2002, Morrongiello \& Schwebal 2017). To ensure fire safety is targeted towards the needs of participants (Kirsch 2016, Lehna et al. 2013) and the risks experienced by communities (Monk 2011), the 'multiple messages-multiple methods' approach should be employed. This approach requires the use of techniques and resources to give children equal access to education that is suitable and relevant (Hickman \& Lawrence 2010, Kirsch 2016). This may include presenting the same message using a variety of modes and media (instruction, role play, video and online interactive resources), the use of translated resources and culturally appropriate fire safety advice and scenarios (Kirsch 2016, Lidstone 2006, Rimmer et al. 2010) and the inclusion of community diversity in publications and illustrations (Gielan et al. 2010).

\section{Content}

\section{Fire safety education should be behaviourally focused}

Fire safety education that is behaviourally focused involves stimulating and interactive activities that transfer knowledge and skill (Jankowski 2015, UK Office of the Deputy Prime Minister 2003). Messages such as 'get down low and go, go, go' to safely exit a room with a smoke layer and 'stop, drop, cover, and roll' when clothing catches alight help teach children how to respond appropriately to fire (Gielser 2017, Hickman \& Lawrence 2010, Huseyin \& Satyen 2006, Kendrick et al. 2007, Smith et al. 2018). These actions are important where a child's behavioural response to fire increases their risk of fire fatality (Chen et al. 2011). 
M RESEARCH

Fire safety education should involve fire escape planning and drills

Although fire safety education often teaches children how to exit a room safely, studies have found that the self-rescue capabilities of children are limited (Najmanova \& Ronchi 2017) At the age of 3 , children are capable of self-preservation and have the capacity to understand and follow simple instructions and walk without support (Taciuc \& Dederichs 2013). They have a limited understanding of risk, an undeveloped sense of danger, a lack of awareness of the need to escape unsafe or dangerous situations and no ability to react promptly and rationally to fires (Chen et al. 2011; Harpur, Boyce \& McConnell 2012; Smith et al. 2018). Younger children also take longer to evacuate than do older children and are more likely to need an adult to accompany them or provide instructions to follow (Harpur, Boyce \& McConnell 2012; Najmanova \& Ronchi 2017; Smith et al. 2018). Older children have the capacity to self-rescue and evacuate unsafe environments without adult support or guidance as older children can have experienced periods of being alone (Giesler 2017). However, evidence indicates that children who are home alone and face an emergency do not know how to respond appropriately (Durso 2013). It is important to educate older children about how to handle emergencies and make the necessary decisions without adult guidance (Giesler 2017).

This highlights the importance of fire escape planning and drills (Chen et al. 2011, Lehna et al. 2013). Teachers and caregivers should guide children through creating and practising fire escape plans at school and home (Gielser 2017). Plans and drills increase fire safety knowledge and accuracy of response to fire (Gielser 2017; Hickman \& Lawrence 2010, Huseyin \& Satyen 2006, Tatebe \& Mutch 2015). Fire escape planning and drills reinforce appropriate behaviour, such as alerting an adult to the alarm or fire, evacuation, going to a pre-arranged safe place and calling emergency services (Mytton, Goodenough \& Novak 2017). It is important to note that fire alarms differ in tone, pitch and rhythm (Dukes et al. 2016) and this may trigger adverse reactions in some children (Cohen 2012). Pre-instruction and repetition are important to assist children to differentiate between fire alarms and other sounds and to be less sensitive to the sound because they know how to respond appropriately (Cohen 2012, Dukes et al. 2016).

Fire safety education should include firefighter identification and awareness

Education that teaches children how to identify a firefighter and the roles of firefighters is effective for improving awareness that firefighters are responsible people in an emergency (Cole, Krandell \& Kourofsky 2004; UK Office of the Deputy Prime Minister 2003). Children need not run or hide from a firefighter in an emergency but should gain their attention and approach them if safe to do so (Giesler 2017). While firefighters should dress in their full uniform during lessons to aid identification, their appearance may initially frighten younger children. It is also important for firefighters to sit or crouch down when speaking with children so that they are on the same level (Giesler 2017).
Fire safety education should include match and lighter safety

Teaching that matches and lighters are used by adults improves children's awareness to tell an adult if they see matches or a lighter (Cole, Krandell \& Kourofsky 2004; Giesler 2017). This can reduce the risk of children playing with matches and lighters (Kendrick et al. 2007) particularly where matches and lighters are associated with an increased risk of fire injury and fatality (Chen et al. 2011, Istre et al. 2001). Evidence suggests that children should be educated about the medical and social consequences of misusing fire (UK Office of the Deputy Prime Minister 2003). However, this finding contrasts with the need to use gainframing. Instead, match and lighter safety should focus on children informing an adult if they see matches and lighters and the positive outcome of that action.

\section{Fire safety education should include messaging about when and how to dial Triple Zero (000)}

Children should be taught to dial Triple Zero (000) by first identifying the circumstances under which to call Triple Zero (000), what happens if they call and possible repercussions of making hoax calls (Hickman \& Lawrence 2010, Towers \& Whybro 2017, UK Office of the Deputy Prime Minister 2003). It is important that children have opportunities to practice dialling Triple Zero (000) using the numbers as they would appear on a phone and learn how to navigate to the emergency dial pad on a phone or mobile (Giesler 2017).

\section{Fire safety education should reinforce messages about bushfire safety}

Due to the heightened risk of bushfire and increased effects of hazards on children, there is a need to reiterate bushfire safety when delivering fire safety education (Brown 2019, Office of the Advocate for Children and Young People 2020). When children are aware of the risk factors for bushfire they are more likely to assist in prevention and preparedness activities (Brown 2019) and improve response and recovery outcomes (Office of the Advocate for Children and Young People 2020). Bushfire education assists children to understand the importance of bushfire escape plans, how and when to implement them, what to pack in readiness and where to go when leaving (Office of the Advocate for Children and Young People 2020). While bushfire education is included in disaster education more broadly, evidence suggests that messages about bushfire safety should be included when delivering fire safety education.

\section{Fire safety education should include fire hazard identifica-} tion and mitigation

Lessons in fire hazard identification and mitigation improve children's understanding of how to identify and react to hazardous situations (Gielser 2017, Morrongiello 2012, Smith et al. 2018, Tatebe \& Mutch 2015). A valid approach is to show children various hazard scenarios, including combustibles stored too close to a heat source, blocked exits, matches and lighters lying around, unsupervised lit candles and cooking as well as overloaded power boards (Morrongiello 2012). 
This should be followed by the ways to reduce these hazards. Education that involves identification and mitigation promotes active engagement in hazard reduction (Office of the Advocate for Children and Young People 2020). Importantly, if children see their contributions implemented, they are more likely to remember the material, have a sense of ownership over their safety and promote safe environments (Office of the Advocate for Children and Young People 2020).

\section{Fire safety education for older children should include fire science}

Fire safety education for older children extends beyond specific fire safety skills (UK Office of the Deputy Prime Minister 2003). Older children need a good level of understanding of fire, the science behind fire and all its characteristics, so they can identify risks and take appropriate actions (UK Office of the Deputy Prime Minister 2003). Fire science lessons should cover what fire is, how it works, why it grows and spreads and how it can be controlled and extinguished (UK Office of the Deputy Prime Minister 2003). Evidence indicates that children appreciate information that provides them with a deeper knowledge of why emergencies, such as bushfires, occur (Office of the Advocate for Children and Young People 2020).

\section{Fire safety education should be relatable to children's lived} experiences of fire

Research shows that children desire opportunities to share their stories and find common understanding with others (Office of the Advocate for Children and Young People 2020). By providing opportunities with their peers, school and their community, children can cognise fire safety messages in a meaningful and relatable manner (Office of the Advocate for Children and Young People 2020). This can enhance the effectiveness of fire safety education. To permit alignment with other evidencebased practices, it is important that children's lived experiences of fire are gain-framed and caregiver mediated. Stories can be completed as homework exercises that encourage family or caregiver discussion. When presented in class, correct behavioural responses can be reinforced by identifying the positive outcomes of behaviours, while incorrect responses can be corrected by focusing on behaviours that can be performed in the future to achieve desirable outcomes.

\section{Resources}

Fire safety education should use resources and create a realistic training environment

Fire safety programs that use resources such as the firefighter uniform, smoke alarms and a pretend phone to dial Triple Zero (000), create a realistic training environment that develops knowledge and skills in a practical environment (Federal Emergency Management Agency n.d.). When children learn in a simulated environment, such as a mock house prop or trailer, they can practice their fire safety skills in situ (Phillips 2012). This helps them identify and respond to hazards and to understand the practical implications of their knowledge and skills (Phillips 2012).
Fire safety education should incorporate digital resources, activities and social media

Many children spend a good proportion of time online, both for education and recreation (Kirsch 2016) and often seek out information online (Durso 2013). Digital resources, activities and social media are cost-effective ways to engage children, disseminate and reiterate fire safety information and implement prevention activities (Morrongiello \& Schwebal 2017, Towers $\&$ Whybro 2017). New research suggests that serious games and augmented/virtual reality can train older children and adolescents to respond to a fire, make sound decisions and evacuate safely (Almeida \& Rossetti 2015, Cakiroglu \& Gokoglu 2019). Serious games recreate situations that are difficult to simulate in the real world with a high degree of immersion and realism. They assist children in transferring their knowledge and skills to the practical environment (Cakiroglu \& Gokoglu 2019).

\section{Teachers should have access to resources and support}

Although teachers are well placed to deliver fire safety education, they are not subject-matter experts. Nor do they have the time or resources to develop comprehensive fire safety programs in isolation (Ogier 2008). As a result, fire services organisations must continue to provide teachers with resources and support to successfully teach fire safety concepts (Brown 2019, Towers et al. 2014, Ogier 2008). Correct and consistent information should be available to teachers to help them implement evidence-based and curriculum-aligned fire safety education (Brown 2019, Towers et al. 2014, Ogier 2008).

\section{Caregivers should have access to resources and support}

Caregivers play a pivotal role in supervising and modelling appropriate fire behaviour for children (Bahr 2000). In fact, it is the behaviour and lifestyles of caregivers, rather than that of children, that are paramount to reducing risk. Caregivers must have access to education and information so that they are aware of the importance of home fire safety, adequate supervision, limiting access to incendiary materials and safe modelling behaviour (Bahr 2000; Gielser 2017; Harpur, Boyce \& McConnell 2012; Istre et al. 2002). Caregivers should be educated in firerelated risks associated with children's developmental stages (Smith et al. 2018) and should know how to identify misuse of fire (Giesler 2017). If caregivers practice safe fire behaviour children are more likely to model this behaviour (Gielser 2017). Further, when caregivers are well-informed, they are more likely to create a safe environment for children (Gielser 2017).

To capitalise on the capacity of caregivers, children could use resources that help them transfer fire safety knowledge from school into the home (Kourofsky \& Cole 2010, Rimmer et al. 2010, Towers et al. 2014). Take-home resources such as checklists, factsheets or homework exercises, help knowledge retention and the transfer of knowledge from children to caregivers extends learning beyond classroom instruction (Chavez et al. 2014, Gielan et al. 2010, Johnson et al. 2014, Lehna et al. 2013, Ogier 2008, Rimmer et al. 2010, Tatebe \& Mutch 2015, UK Office of the Deputy Prime Minister 2003). While this would be ideal, the provision of take-home resources may rely 
on the available resources of fire service organisations and budgetary allocations.

\section{Fire safety education should provide free or low-cost fire safety equipment}

Fire-related injury is heightened by the absence of smoke alarms (Kendrick et al. 2012) and poor smoke alarm functionality (Chen et al. 2011, Kendrick et al. 2012). Fire safety initiatives that provide free or low-cost fire safety equipment, such as smoke alarms, are effective at improving home fire safety (Dierkman, Ballesterous \& Ahrens 2011; Kendrick et al. 2012; Smith et al. 2018). Importantly, the provision of fire safety equipment is effective for families whose children are at greater risk of injury (Dierkman, Ballesterous \& Ahrens 2011; Kendrick et al. 2012). However, smoke alarms are not sufficient to reduce the risk of fire-related injury and fatality (Istre et al. 2002, Smith et al. 2018). Consequently, the provision of fire safety equipment, such as smoke alarms, should be accompanied by additional caregiver resources.

\section{Implementation}

Fire safety education should be embedded in business-as-usual activities and programs should be designed to provide consistency in implementation

Fire safety education should be embedded in business-asusual for fire services organisations through recruit training, career development and normal workplace practices (Monk 2011, UK Office of the Deputy Prime Minister 2003). Fire services organisations should form ongoing relationships with local schools to conduct regular fire safety sessions within the curriculum (Ogier 2008). It is recognised that negative firefighter attitude towards fire safety education in schools may impede effectiveness, so it is important that firefighters are correctly chosen to deliver sessions and they are aware of the value of fire safety and its implications for the health and safety of children and their families (Ogier 2008). Firefighters can be allowed ownership over the provision and delivery of the program to encourage commitment (Ogier 2008). Fire safety programs should be designed to allow for consistency in delivery (Gerald 2019, Phillips 2012). Participating firefighters must be provided with training that helps in the systematic delivery of fire safety education (Gerald 2019, Monk 2011, UK Office of the Deputy Prime Minister 2003).

\section{Evaluation}

Fire safety education programs should be subject to record keeping, monitoring and evaluation

Fire safety education programs should be subject to scrutiny to ensure they are relevant, effective and evidence-based (Giesler 2017, Monk 2011, Lidstone 2006, Towers et al. 2014). Although it is important to measure post-implementation changes in knowledge, it may be difficult to measure how children behave in emergency situations or if fire safety education changes a child's behaviour (Johnson et al. 2014). Where fire safety knowledge does not always lead to the practical application of fire safety skills and prevention in the home (Senthilkumaran et al. 2019), measuring knowledge alone is insufficient. Despite this, fire safety knowledge is a precursor of behavioural change (Senthilkumaran et al. 2019). Evaluation mechanisms should measure fire safety knowledge and behaviour in children and their caregivers before and after program implementation by using qualitative and quantitative instruments (Gielan et al. 2010, Johnson et al. 2014, Senthilkumaran et al. 2019). Instruments may include surveys of home fire safety practices, skill testing, drills, fire scenarios and other activities that measure knowledge and behavioural change (Gerald 2019).

\section{Conclusion}

Fire safety education helps to reduce the likelihood children will misuse fire or be harmed by fire. Although there is a large body of evidence informing current practice, there are no overarching, evidence-based frameworks guiding effective education programs. Such guidelines are needed to develop new programs and to evaluate and modify existing ones.

Fire safety education is most effective when underpinned by comprehensible change theory, mapped against the education curriculum and delivered by teachers and reinforced by firefighters. Lessons incorporating CCDRR principles and that are behaviourally focused can improve fire safety knowledge and skills in children. Actual, interactive and online resources facilitate the acquisition and transfer of knowledge and skills to the practical environment, while teacher and caregiver resources support the delivery and reinforce fire safety messages. When programs are embedded within business-as-usual activities, fire services organisations can establish consistency in implementation and ongoing record keeping, monitoring and evaluation. The use of an overarching, evidence-based framework will deliver the rigour, consistency and effectiveness of fire safety education.

\section{Acknowledgments}

Julie Wyner, the Community Engagement Unit and Fire and Rescue New South Wales are acknowledged for their support of this research. The views expressed herein do not necessarily represent any official views of Fire and Rescue New South Wales.

\section{References}

Almeida J \& Rossetti R 2015, Using serious games to train children and elicit fire safety behaviour. World CIST, April 1-3, 2015, Azores, Portugal.

Back E, Cameron C \& Tanner T 2009, Children and disaster risk reduction: taking stock and moving forward. At: www. researchgate.net/publication/265184281_Children_and_ Disaster_Risk_Reduction_Taking_Stock_and_Moving_Forward [24 August 2020].

Bahr P 2000, A false sense of security: A study into children's access to cigarette lighters and their use as a fire lighting tool. Theses and Dissertations, University of South Australia. 
Barends E, Rousseau D \& Briner R 2017, CEBMa Guideline for Rapid Evidence Assessments in Management and Organisations (version 1). Centre for Evidence Based Management, Amsterdam. At: https://cebma.org/wp-content/uploads/CEBMa-REA-Guideline. pdf [24 August 2020].

Borzekowski D, Clearfield E, Rimal R \& Gielan A 2013, Young children's perceptions of fire safety messages: Do framing and parental mediation matter? Journal of Burn Care and Research, vol. 35, pp.303-312.

Brown L 2019, Child-centred disaster resilience education in Australia's north-west. Australian Journal of Emergency Management, vol. 34, no. 3, pp.22-23. At: https://knowledge.aidr. org.au/resources/ajem-july-2019-child-centred-disaster-resilienceeducation-in-australias-north-west/.

Cakiroglu U \& Gokoglu S 2019, Development of fire safety behaviour skills via virtual reality. Computers \& Education, vol. 113, pp.56-68. doi:10.1016/j.compedu.2019.01.014

Chavez A, Duzinski S, Wheeler T \& Lawson K 2014, Teaching safety at a summer camp: Evaluation of a fire safety curriculum in an urban community setting. Burns, vol. 40, no. 6, pp.1172-78. doi:10.1016/j.burns.2013.12.006

Chen Y, Bridgeman-Acker K, Edwards J \& Lauwers A 2011, Pediatric fire deaths in Ontario: a retrospective study of behavioural, social, and environmental risk factors. Canadian Family Physician, vol. 57, pp.169-177.

Cohen D 2012, Children with Autism and fire drills and fire alarms. Mountain Brook Fire Department, Alabama. At: www.hsdl. org/?view\&did=804455 [24 August 2020].

Cole R, Krandell R \& Kourofsky C 2004, We can teach young children fire safety. Young Children, vol. 59, no. 2, pp.14-18.

Dierkman S, Ballestros M \& Ahrens M 2011, Home fires in America: progress and opportunities. American Journal of Lifestyle Medicine, vol. 6, no. 2, pp.141-151.

Dukes C, Brady M, Scott J \& Wilson C 2016, Using modelling and rehearsal to teach fire safety to children with autism. Journal of Applied Behaviour and Analysis, vol. 49, pp.699-704.

Durso F 2013, Young + Fire Smart: NFPA develops a youth program on wildfire safety. NFPA Journal, March/April: pp.11-12. At: https://search.proquest.com/trade-journals/young-fire-smart/ docview/1326420317/se-2?accountid=30642 [24 August 2020].

Federal Emergency Management Agency n.d, Fire safety trailer curriculum: Tools for developing FSE messages using a fire safety trailer. At: www.usfa.fema.gov/downloads/pdf/publications/ fire_safety_trailer_curriculum.pdf [24 August 2020].

Gerald J 2019, Descriptive analysis of public education for children. Baton Rouge Fire Department, Louisiana. At: https:// usfa.kohalibrary.com/app/work/249849 [24 August 2020].

Gielan A, Borzekowski D, Rima R \& Kumar A 2010, Evaluating and creating fire and life safety materials: a guide for the fire service. At: www.nfpa.org/-/media/Files/Public-Education/Resources/
Educational-messaging/EMAC/NFPAGuideForTheFireService.pdf [24 August 2020].

Gielan A, Borzekowski D \& Rimal R 2010, Understanding the impact of fire and life safety messages on children. At: www.nfpa.org/ / media/files/public-education/resources/educational-messaging/ johnshopkinsmessagingreport.pdf?la=en [24 August 2020].

Giesler M 2017, Fire and life safety educator: principles and practices (2nd ed.). Jones and Bartlett Learning, Massachusetts.

Harpur A, Boyce K \& McConnell N 2012, An investigation into the circumstances surrounding fatal dwelling fires involving very young children. Fire Safety Journal, vol. 61, pp.72-82.

Haynes K, Lassa J \& Towers B 2010, Child centred disaster risk reduction and climate change adaption: roles of gender and culture in Indonesia. At: www.researchgate.net/ publication/210194710_Child_centred_disaster_risk_reduction_ and_climate_change_adaptation_roles_of_gender_and_ culture_in_Indonesia [24 August 2020].

Huseyin I \& Satyen L 2006, Fire safety training: its importance in enhancing fire safety knowledge and response to fire. Australian Journal of Emergency Management, vol. 21, no. 4, pp.48-53.

Istre G, McCoy M, Carlin D \& McClain J 2002, Residential fire related deaths and injuries among children: fireplay, smoke alarms, and prevention. Injury Prevention, vol. 8, pp.128-132.

Jankowski P 2015, Evaluating FSE outreach in K-5 students in La Verne. La Verne Fire Department, California. At: https://usfa. kohalibrary.com/app/work/234045 [24 August 2020].

Johnson V, Ronan K, Johnston D \& Pease R 2014, Evaluations of disaster education programs for children: a methodological review. International Journal of Disaster Risk Reduction, vol. 9, pp.107-123.

Kendrick D, Young B, Mason-Jones AJ, llyas N, Achana FA, Cooper NJ, Hubbard SJ, Sutton AJ, Smith S, Wynn P, Mulvaney C, Watson MC \& Coupland C 2012, Home safety education and provision of safety equipment for injury prevention (review). Evidence based child health: a Cochrane Review Journal, vol. 8, no. 3, pp.761-939.

Kendrick D, Groom L, Stewart J, Watson M, Mulvaney C \& Casterton R 2007, "Risk Watch": Cluster randomised controlled trial evaluating an injury prevention program. Injury Prevention, vol. 13, pp.93-98.

Kirsch J 2016, Determining needs of minority populations in order to promote fire safety programs. Bergenfield Fire Department, New Jersey. At: https://usfa.kohalibrary.com/app/work/237666. [24 August 2020].

Kourofsky C \& Cole R 2010, Young children can be key to fire-safe families. Young Children, vol. 65, no. 3, pp.84-87.

Lehna C, Janes DG, Renges S, Graviss J, Scrivener D, Knabel T \& Myres J 2013, Impact of children with special needs on differences in fire-safety education priorities, preferred method of education, and parent actions. Journal of Burn Care \& Research, vol. 35, no. 2, pp.162-168. 
Lidstone J 2006, Blazer to the rescue! The role of puppetry in enhancing fire prevention and preparedness for young children. Australian Journal of Emergency Management, vol. 21, no. 2, pp.17-28. At: https://knowledge.aidr.org.au/resources/ajem-may2006-blazer-to-the-rescue-the-role-of-puppetry-in-enhancingfire-prevention-and-preparedness-for-young-children/.

Monk J 2011, Fire prevention and life safety education in schools: a collaborative effort. Hampton Division of Fire and Rescue, Virginia. At: www.semanticscholar.org/paper/Fire-Preventionand-Life-Safety-Education-in-A-Monk [24 August 2020].

Morrongiello B 2012, Innovations in child injury prevention: evidence-based strategies that address fire safety for young children and playground safety for older children. Injury Prevention, vol. 18, pp.A1-A246.

Morrongiello B \& Schwebal D 2017, Pediatric psychology and child unintentional injury prevention: current state and future directions for the field. Journal of Pediatric Psychology, pp.721-726.

Mytton J, Goodenough T \& Novak C 2017, Children and young people's behaviour in accidental dwelling fires: a systematic review of the qualitative literature. Safety Science, vol. 96, pp.143-149.

Najmanova H \& Ronchi E 2017, An experimental data-set on preschool children evacuation. Fire Technology, vol. 53, pp.1509-1533.

Ogier S 2008, Evaluation of the Firewise Programme for year one and two students: final report. At: https://fireandemergency. $n z /$ assets/Documents/Teachers-and-schools/Research_ FirewiseEvaluationMartinJenkins.pdf [24 August 2020].

Phillips M 2012, Evaluation of the Cedar City Fire Department's fire prevention and life safety house program. Cedar City Fire Department, Utah. At: https://usfa.kohalibrary.com/app/ work/175844 [24 August 2020].

Office of the Advocate for Children and Young People 2020, Children and young people's experience of disaster. At: www.acyp. nsw.gov.au/disaster-report-2020 [24 August 2020].

Rimmer RB, Pressman M, Joiner J, Winchester S, Foster KN \& Caruso DM 2010, The effectiveness of a culturally sensitive burn and fire prevention program designed for inner city school students and parents. Injury Prevention, vol. 16, pp.A1-A289.

Ronan K \& Towers B 2014, Systems education for a sustainable planet: preparing children for natural disasters. Systems, vol. 2, pp.1-23.

Satyen L, Barnett M \& Sosa A 2004, Effectiveness of fire safety education in primary school children. Human Behaviour in Fire: Public Fire Safety Professionals in Partnership, 3rd International Symposium. Belfast, Northern Ireland: Interscience Communications.

Senthilkumara M, Nazari G, MacDermid J \& Roche K 2019, Effectiveness of home fire safety interventions: a systematic review and meta-analysis. PLos ONE, vol. 14, no. 5, pp.1-17.

Simpson T, Wheatley D, Brunsden V \& Hill R 2014, Fire and rescue service community safety initiatives: measuring impact. Safer Communities, vol. 13, no. 2, pp.88-100.
Smith J, Dhinsa A, Rajabali F, Zheng A, Bruin S \& Pike I 2018, The epidemiology of residential fires among children and youth in Canada. At: https://cjr.ufv.ca/wp-content/uploads/2018/04/UBCEpidemiology-of-Residential-Fires-Children-and-Youth.pdf [24 August 2020].

Subramaniam C 2004, Human factors influencing fire safety measures. Disaster Prevention and Management, vol. 13, no. 2, pp.110-116.

Tacuic A \& Dederichs A 2013, Determining self-preservation capability in pre-school children. At: www.nfpa.org/News-andResearch/Data-research-and-tools/Building-and-Life-Safety/ Determining-Self-Preservation-Capability-in-Pre-School-Children [24 August 2020].

Tatebe J \& Mutch C 2015, Perspectives on education, children and young people in disaster risk reduction. International Journal of Disaster Risk Reduction, vol. 14, pp.108-114.

Towers B \& Whybro M 2017, A formative evaluation of the Triple Zero Kids' Challenge Teacher's Guide. Australian Journal of Emergency Management, vol. 33, no. 3, pp. 64-70. At: https:// knowledge.aidr.org.au/resources/ajem-jul-2018-a-formativeevaluation-of-the-triple-zero-kids-challenge-teacher-s-guide/.

Towers B, Haynes K, Sewell F, Bailie H \& Cross D 2014, Childcentred disaster risk reduction in Australia: progress, gaps and opportunities. Australian Journal of Emergency Management, vol. 29, no. 1, pp.31-38.

UK Office of the Deputy Prime Minister 2003, Working with young people in the community. At: https://webarchive.nationalarchives. gov.uk/20060619133258/http://www.communities.gov.uk/index. asp?id=1162371 [24 August 2020].

Varker T, Forbes D, Dell L, Weston A, Merlin T, Hodson S \& O'Donnell M 2015, Rapid evidence assessment: Increasing the transparency of an emerging methodology. Journal of Evaluation in Clinical Practice, vol. 21, no. 5, pp.1199-1204.

\section{About the authors}

Dr Kamarah Pooley is a senior firefighter with Fire and Rescue New South Wales who works with the Community Safety and Research Directorate. She has a PhD in youth misuse of fire and conducts research in issues concerning young people, fire prevention and community risk reduction.

Sonia Nunez is a firefighter with Fire and Rescue New South Wales who works with the Community Safety and Research Directorate.

Mark Whybro was the Fire and Rescue New South Wales Assistant Commissioner of Community Safety and retired in 2020. 